Meta

Journal des traducteurs

Translators' Journal

\title{
Tratamiento de ritmo y rima en las traducciones al español de los Sonetos de Shakespeare
}

\section{Tanya Fernández Escudero}

Volume 62, numéro 2, août 2017

URI : https://id.erudit.org/iderudit/1041028ar

DOI : https://doi.org/10.7202/1041028ar

Aller au sommaire du numéro

\section{Éditeur(s)}

Les Presses de l’Université de Montréal

ISSN

0026-0452 (imprimé)

1492-1421 (numérique)

Découvrir la revue

Citer cet article

Fernández Escudero, T. (2017). Tratamiento de ritmo y rima en las traducciones al español de los Sonetos de Shakespeare. Meta, 62(2), 350-367. https://doi.org/10.7202/1041028ar
Résumé de l'article

Sur la base des définitions de vers, rythme, et rime et des caractéristiques du sonnet dans les poésies lyriques anglo-saxonne et hispanique, cette étude analyse formellement le système métrique d'un corpus constitué de onze traductions vers l'espagnol des Sonnets de Shakespeare (1609) publiés en Espagne entre les années 1990 et 2013. Pour cette analyse, nous avons fait attention à trois éléments fondamentaux : la mesure du vers, l'emplacement des accents dans le vers et le type de rime employé par le traducteur afin d'y observer le traitement du rythme et de la rime, et de tirer des conclusions sur le degré de similitude formelle entre la traduction et le texte original. Ce degré de similitude a été établi à partir d'un listage graduel de possibles correspondances en espagnol pour le pentamètre ïambique utilisé par Shakespeare dans ses compositions. 


\title{
Tratamiento de ritmo y rima en las traducciones al español de los Sonetos de Shakespeare
}

\author{
TANYA FERNÁNDEZ ESCUDERO \\ Universidade de Vigo, Vigo, España \\ tanyaescudero@gmail.com
}

\section{RESUMÉ}

Sur la base des définitions de vers, rythme, et rime et des caractéristiques du sonnet dans les poésies lyriques anglo-saxonne et hispanique, cette étude analyse formellement le système métrique d'un corpus constitué de onze traductions vers l'espagnol des Sonnets de Shakespeare (1609) publiés en Espagne entre les années 1990 et 2013. Pour cette analyse, nous avons fait attention à trois éléments fondamentaux: la mesure du vers, l'emplacement des accents dans le vers et le type de rime employé par le traducteur afin d'y observer le traitement du rythme et de la rime, et de tirer des conclusions sur le degré de similitude formelle entre la traduction et le texte original. Ce degré de similitude a été établi à partir d'un listage graduel de possibles correspondances en espagnol pour le pentamètre ïambique utilisé par Shakespeare dans ses compositions.

\begin{abstract}
Based on the definitions of verse, rhythm and rhyme and the sonnet's features in both English and Spanish lyrical poetry, this study formally analyzes the meter of a corpus consisting of eleven translations of Shakespeare's Sonnets (1609) into Spanish, all of them published in Spain between 1990 and 2013. For this analysis we have paid attention to three essential aspects: verse length, stressed syllables pattern and the type of rhyme used by the translator. This has been made in order to observe the rhythm and rhyme treatment in them and draw some conclusions about the degree of formal similarity between the translation and the source text. This degree of similarity has been established from a gradual list of potential correspondences in Spanish for the iambic pentameter used by Shakespeare in his poems.
\end{abstract}

\section{RESUMEN}

Basándonos en las definiciones de verso, ritmo y rima y de las características del soneto tanto en la lírica hispánica como en la anglosajona, este estudio pretende analizar formalmente la métrica de un corpus formado por once traducciones al español de los Sonetos de Shakespeare (1609), publicados en España entre los años 1990 y 2013. Para este análisis, nos hemos centrado en tres aspectos esenciales: la medida del verso (su cómputo silábico), el patrón acentual o rítmico y el tipo de rima empleada por el traductor, con el fin de observar el tratamiento del ritmo y de la rima y de extraer conclusiones sobre el grado de similitud formal entre la traducción y el texto original. Este semejanza se ha establecido a partir de una lista gradual de posibles correspondencias en español para el pentámetro yámbico empleado por Shakespeare en sus composiciones.

\section{MOTS-CLÉS/ KEYWORDS/ PALABRAS CLAVE}

rythme, rime, traduction, sonnets, Shakespeare rhythm, rhyme, translation, sonnets, Shakespeare ritmo, rima, traducción, sonetos, Shakespeare 


\section{Introducción}

\subsection{La traducción de poesía y la «fidelidad»}

La inmensa parte de las reflexiones y debates que pueden encontrarse sobre la traducción poética parten de una idea que, si bien está presente en todo proceso de traducción, es aún más evidente en el campo que nos ocupa; se trata de la noción de fidelidad. Esta idea planea sobre la cabeza del traductor de poesía más que sobre la de cualquier otro, pues su labor no consiste ya solo en transmitir una información, sino en acercarle al lector una suma de estilo y entramado semántico que aparece en las composiciones del autor original. Amparo Hurtado Albir la define como «la relación idónea que el traductor ha de entablar con el texto original». Ahora bien, como apunta la autora, «el problema surge cuando se trata de responder a qué hay que ser fiel» (1990a:58). Hurtado Albir afirma que el traductor debe mantenerse fiel a tres principios: a la intención del autor, a la lengua meta y al lector o destinatario de la traducción (1990b:118).

En las reflexiones que giran en torno a la traducción poética, es la primera de estas tres la que tiene más peso, la fidelidad al autor, pues como señala Venuti: «translation is defined as a second-order representation: only the foreign text can be original, an authentic copy, true to the author's personality or intention, whereas the translation is derivative, fake, pontentially a false copy» (1995:6-7).

Jorge Luis Borges, en Las dos maneras de traducir (Borges 1997) también se refiere a esta opinión generalizada:

Suele presuponerse que cualquier texto original es incorregible de puro bueno, y que los traductores son unos chapuceros irreparables, padres del frangollo y de la mentira. Se les infiere la sentencia italiana de traduttore traditore y ese chiste basta para condenarlos [...] Esa reverencia del yo, de la irreemplazable diferenciación humana que es cualquier yo, justifica la literalidad en las traducciones. Además, lo lejano, lo forastero, es siempre belleza (Borges 1997: 256)

El autor y traductor argentino considera una «superstición» esa idea de que un original sea siempre mejor que su traducción y defiende la recreación en la traducción poética. Esta es también la postura de Rafael Morales Barba, quien afirma que «la labor del buen traductor está destinada a la recreación por definición. No de otra manera se puede enfrentar a la reconstrucción verbal que radicaliza su puridad y sentido, periodo y reglamentación convencional» (1996:180). Bien es cierto que una traducción puede mejorar la calidad del original, no obstante, ¿es este el motivo de la fidelidad al autor? Cuando el traductor se libera de su sumisión a ella puede, ciertamente, crear un texto mejor que aquel del que ha partido, pero ¿qué queda de este en la traducción? ¿Cuándo deja un escrito de ser una traducción para convertirse en una obra nueva a partir de algunos retazos de otro texto previo? Esta es, sin duda, una línea muy difícil de trazar y para la que los traductores y los traductólogos no han desarrollado aún herramientas de reflexión eficaces.

Sin embargo, no es este el único debate que abre la noción de fidelidad. En la «Introducción» a las Obras Completas de Shakespeare, Luis Astrana Marín explica que «hay varias opiniones sobre si se debe traducir a un poeta en verso» y manifiesta tajante que «puede asegurarse que ninguna traducción en verso es buena. [...] La razón obedece a que unas veces la métrica y otras la rima impiden permanecer fieles al autor» (Shakespeare, 2003:17). Astrana se refiere aquí a la métrica y la rima como 
un impedimento en pro de la transmisión del componente semántico, pero ¿por qué ha de tener la fidelidad al contenido más valor que aquella que busca mantener la forma si como señala Valéry «la fidélité restreinte au sens est une manière de trahison»? (en Carandell, 2006:4). Al fin y al cabo, ¿no es el verso, como veremos más adelante ( $c f$. Quilis:1978:3), esencialmente forma? En un punto intermedio, Robert de Beaugrande afirma que en la traducción poética ha de haber una fase añadida respecto a otro tipo de traducción: «The reworking of a communicationally equivalent translation toward a version wich also maintains a high formal correspondance», pero establece $-y$ aquí podemos apreciar claramente el carácter prescriptivo de este texto- que «the priorities and the work sequence must be in this order and not vice versa. The communicative directives must be primary, and those of form secondary» (1978:98-99, la cursiva es nuestra).

Esta controversia deriva de una de las principales dificultades en la traducción de poesía: la traslación a otra lengua de un texto formado por dos componentes aquí íntimamente ligados - quizás indisolubles- como son el contenido (entendido no solo como conjunto de significados, sino como un engranaje de mecanismos retóricos que juegan con aquellos) y la expresión (suma de una estructura precisa, de unos elementos rítmicos que se originan en la métrica del poema y en la repetición fonética y, en ocasiones, de la rima).

\subsection{Objetivos e hipótesis de trabajo}

En el caso del soneto, esa relación entre expresión y contenido a la que aludíamos es clara, pues el revestimiento formal, como comprobaremos, es definitorio en este tipo de composición. Partiendo de este carácter esencial de la métrica, hemos observado las estrategias de traducción respecto al ritmo y la rima que han llevado a cabo los traductores de los Sonetos de Shakespeare con el fin de responder, al término de este estudio, a las tres preguntas de las que partiremos y que se basan en la labor del traductor cuando este se enfrenta a la traslación de una composición poética prescrita como es el soneto, común en las líricas correspondientes a sus dos lenguas de trabajo y con larga tradición y peso en ambas.

El primer interrogante que nos planteamos es: ¿el traductor de poesía, al enfrentarse a la traducción de un soneto, opta por verter el poema original en forma de verso o de prosa?

Nuestra segunda pregunta se centra en el metro empleado: ¿el traductor de poesía intenta trasladar a la lengua meta el ritmo original? Para responder a esta cuestión tendremos en cuenta las diferencias métricas entre los sistemas de las dos lenguas con las que trabaja. Además, entendemos, que la resolución será menos concluyente, pues los criterios en que se basa el concepto de ritmo (que aparecen definidos en el punto 2.1.) no están tan bien delimitados. Además, las características de los sistemas métricos inglés y español varían (como se explica en los apartados 2.2. y 2.3.), por lo que no se dan equivalencias exactas entre metros.

Por último, y debido a la relación intrínseca entre soneto y rima que explicaremos también en este estudio, creemos conveniente formular una tercera pregunta: ¿el traductor busca un efecto sonoro equivalente en el poema de llegada a través de la rima? Para comprobarlo, claro está, no olvidaremos las peculiaridades de este recurso tanto en el sistema de la lengua de ambos idiomas, como en su tradición lírica. 


\subsection{Selección del corpus}

La elección de esta obra obedece a dos motivos fundamentales. Por un lado, el soneto cuenta con una larga tradición en las líricas anglosajona e hispánica, y en ambas comparte el mismo origen, pese a que su evolución ha diferido, debido también a la necesidad de adaptarse a los correspondientes sistemas métricos y a las peculiaridades de cada lengua -en las próximas páginas veremos con mayor detenimiento tanto sus características formales como su evolución. Este devenir paralelo hace que el lector de las dos lenguas, de manera casi inmediata, identifique dicha composición poética como «soneto». En realidad, pocas son las composiciones en que puede establecerse una correspondencia tan clara en dos literaturas tan diferentes.

Por otro lado, el enorme éxito de la obra, primero en la literatura anglosajona y, más tarde, en la nuestra, ha dado lugar a un gran número de traducciones, tanto del poemario completo como de algunos de los poemas, insertados en antologías. Esto nos ha permitido trabajar con un corpus más amplio, y así observar diferentes estrategias y contrastar los resultados.

Una vez delimitada la obra empleada en nuestro análisis y dado que, como comentábamos anteriormente, las traducciones de esta son numerosas, hemos seguido varios criterios en la selección de las traducciones.

En primer lugar, hemos trabajado con ediciones publicadas en España, por estar traducidas a nuestra variante lingüística y con el fin de delimitar un corpus abarcable en este artículo, y siempre de la obra completa, pues consideramos que las estrategias seguidas por el traductor pueden variar de forma considerable según se enfrente a un puñado de poemas seleccionados por él mismo o a todo el conjunto de sonetos. Entendemos que las dificultades añadidas que entraña esta segunda posibilidad forman parte fundamental de la labor del traductor de poesía.

En segundo lugar, hemos seleccionado traducciones publicadas a partir de 1987, ya que el estudio realizado por Micaela Muñoz Calvo, Ediciones y traducciones españolas de los sonetos de William Shakespeare (Calvo 1988), incluye las traducciones publicadas en español hasta esta fecha. Hemos tomado esta decisión con el fin de no solapar nuestro trabajo con el de la autora y también de fijar un corpus abarcable, pero cuyos resultados fuesen relevantes. Si bien es cierto que Muñoz Calvo se centra en los aspectos semánticos y sintácticos, su trabajo, en el que analiza las traducciones de diez de los Sonetos de Shakespeare, hace referencia a algunos aspectos formales, como la rima, la medida y ciertos recursos fónicos.

Por último, y como no podía ser de otro modo, el criterio definitivo en esta selección es la accesibilidad a las fuentes. Que la fama de los sonetos haya dado lugar a múltiples traducciones no implica que todas ellas hayan gozado de éxito, con lo que algunas aparecen ya descatalogadas.

Basándonos, por tanto, en estos criterios hemos acotado un corpus de once traducciones, a saber:

- la de Carlos Pujol, publicada por la editorial Comares (1990);

- la de Pablo Mañé Garzón, publicada por Ediciones 29 (1992);

- la de José Ma Álvarez, publicada por Pre-textos (1999);

- la de Alfredo Gómez Gil, publicada por Edaf (2000);

- la de Antonio Rivero Taravillo, publicada por Renacimiento (2004);

- la de Gustavo Falaquera, publicada por Hiperión (2005)

- la de Ignacio Gamen, publicada por Renacimiento (2009); 
- la de Andrés Ehrenhaus, publicada por Galaxia Gutenberg (2009);

- la de Christian Law Palacín, publicada por Bastleby (2009);

- la de Ramón Gutiérrez Izquierdo, publicada por Visor (2011);

- y la de Bernardo Santano Moreno, publicada por Acantilado (2013).

En los próximos apartados ofreceremos algunos apuntes sobre las nociones de verso, ritmo y rima y las peculiaridades del soneto en las dos tradiciones que nos ocupan, así como las características de los sonetos shakespearianos, para aplicarlos posteriormente a nuestro análisis.

\section{Contextualización}

\subsection{Nociones de verso, ritmo y rima}

Comenzaremos, como es obvio, por tratar de ofrecer una definición de los conceptos claves de este trabajo como son poesía (o bien verso), ritmo y rima, pese a la dificultad que entraña acotar los valores de estos términos.

Navarro Tomás entiende el verso como una «serie de palabras cuya disposición produce un determinado efecto rítmico» (1995: 34-35). Esta relación intrínseca entre verso y ritmo es evidente también para Antonio Quilis que define el poema como:

contexto lingüístico en el cual el lenguaje, tomado en su conjunto de significante y significado como materia artística, alcanza una nueva dimensión formal que, en virtud de la intención del poeta, se realiza potenciando los valores expresivos del lenguaje por medio de un ritmo pleno (Quilis, 1978:13).

Elena Varela Merino va más allá y afirma que «la primera percepción del verso pone de relieve características fonéticas y musicales [...] que, al seguir transmitiendo contenido semántico, adquieren particular extrañeza o belleza» (2005:19). Para ella los «sonidos y pausas» que desencadena el verso desde su aparición «son la sustancia misma de su existencia» (2005:23).

Parece claro, por tanto, que el ritmo es parte fundamental del verso, del poema, pero ¿qué es exactamente ese «ritmo pleno» al que se refiere Quilis? El fonetista considera que se trata de «una especial ordenación de los elementos que constituyen la cadena hablada» y añade que «si estos elementos están sometidos a un canon estructural de simetría y regularidad, se constituye el periodo rítmico que denominamos estrofa» (1978: 13-14, la cursiva es del autor). También alude Quilis a la belleza a la que hacía referencia Varela Merino, sosteniendo que depende en gran parte de «la posición de las sílabas acentuadas» (1978: 19). Este es el caso del español, donde el ritmo se asienta fundamentalmente sobre los apoyos del acento espiratorio, pero no sucede lo mismo en todas las lenguas; y este hecho es uno de los mayores retos con los que se enfrenta el traductor de poesía.

Sin embargo, estas definiciones basadas en nociones abstractas como «características fonéticas y musicales» o «especial ordenación» no aportan una idea exacta y aplicable a la práctica de qué secuencia es rítmica y cuál no lo es y, por tanto, no permite dibujar una frontera clara entre lo que es un poema (un conjunto de versos) o simplemente un texto dividido en líneas más o menos regulares. También esto provocará opiniones diversas -a veces enfrentadas- en diferentes autores y traductores.

No obstante, hay un concepto entre los que nos toca tratar que parece claro, pues descansa en principios fonológicos bien delimitados: así la rima es «la total o parcial 
identidad acústica, entre dos o más versos, de los fonemas situados a partir de la última vocal acentuada» (Quilis, 1978: 31). Esta rima es total o consonante cuando todos los fonemas a partir de la última vocal acentuada coinciden en varios versos, mientras que se denomina parcial o asonante a la rima en la que solo se reiteran los fonemas vocálicos a partir de la última vocal acentuada. A lo largo de este estudio observaremos cómo, pese a que su identificación resulta más evidente que la del ritmo, la rima será la gran olvidada en las traducciones poéticas.

No podemos negar que el componente semántico tiene un gran peso en la creación poética (como demuestran también las numerosas páginas dedicadas a las figuras retóricas de contenido), pero de lo visto anteriormente se deriva que es su composición formal la que la define y acota.

\subsection{El soneto en las tradiciones anglosajona e hispánica}

El soneto nace en Italia de la mano de Giacomo da Lentino en torno al 1230, pero no es hasta el siglo siguiente cuando alcanza la fama gracias a Petrarca (Fuller 1984: 1). Tal y como afirma Michael Spiller «the sonnet is probably the longest-lived of all poetic forms, and certainly the longest-lived of all prescribed forms [...], whose duration and shape are determined before the poet begins to write» (1992: 2, la cursiva es del autor). Pero no se trata solo de la forma prescrita más longeva sino, posiblemente, de la más cultivada por los poetas occidentales.

Aunque Juan de Villalpando había realizado algún intento, fue el Marqués de Santillana quien la introdujo en nuestra lírica a mediados del siglo XV. Santillana fue el primero en tratar de adaptar el endecasílabo italiano, que carecía de tradición en español, pero no tuvo apenas divulgación en su época. Es por ello que tanto Boscán como Garcilaso tomaron como modelo a Petrarca para realizar sus sonetos y de él heredaron también el esquema clásico: dos cuartetos con rima abrazada (ABBA$\mathrm{ABBA})$ y dos tercetos encadenados (CDC-DCD), aunque se emplearon otras combinaciones para los tercetos, CDE-CDE, CDD-CDD, CDE-DCE, etc. (López Hernández 1998: 9-12). En el Siglo de Oro el soneto alcanza su máximo esplendor y se convierte en «la composición preferida entre las estrofas endecasílabas» (Navarro Tomás 1995: 252).

Su inclusión en la lírica inglesa es más tardía. Wyatt la introduce a principios del siglo XVI, pero no se inclina por el esquema clásico sino que opta por tres cuartetos de rima alterna (ABAB-CDCD-EFEF) y un pareado final (GG) (Spiller 1992: 3). Algunos autores atribuyen este cambio a una peculiar lectura del soneto clásico por parte de Wyatt, que habría interpretado las composiciones rematadas en tercetos con rima gemela (CDD-CDD) como un cuarteto y un pareado final (CDDC-DD). Sin embargo, como señala Fuller, lo más probable es que este resultado fuese fruto del afán experimentalista del poeta inglés (Fuller 1984: 15). Pese a que algunos autores como Hopkins o W. H. Auden cultivaron el esquema clásico, la mayoría emplearon el soneto inglés iniciado por Wyatt o soneto isabelino, también denominado shakespeariano, pues como tantos otros el poeta y dramaturgo inglés se decantó por esta variedad que, gracias a él, gozó de un gran éxito en la lírica anglosajona. Este esquema consta, por tanto, de siete rimas en lugar de cuatro o cinco (dos para cada cuarteto y una para el pareado), la razón la explica Fuller: 
«There is no doubt that English poets, finding their language harder to rhyme in than Italian poets, clung to a sonnet in seven rhymes as something of itself more congenial than a sonnet in four or five rhymes» (Fuller 1984: 15)

Algunos poetas españoles, como Antonio Machado, utilizaron este esquema en varias de sus composiciones -quizás, como apunta Quilis, en el caso del andaluz «se deba a un intento de imitar el soneto llamado shakespeariano» (Quilis 1978: 137)-, pero en conjunto no tuvo gran repercusión entre ellos, pues los poemas de Shakespeare no fueron traducidos a nuestra lengua hasta bien entrado el siglo XIX.

El metro elegido por la mayor parte de los sonetistas españoles e hispanoamericanos ha sido el endecasílabo (Navarro Tomás 1995, 202-203). Como afirma Varela Merino «se deduce que es el verso más complejo y rico» y esto se debe a que «es el verso silábicamente más largo que no se rompe en unidades menores de funcionamiento autónomo» (Varela Merino 2005: 81). No obstante, se experimenta con otras medidas como el soneto en alejandrinos o en octosílabos (o sonetillo), especialmente entre los modernistas (López Hernández 1998: 16).

En la lírica anglosajona, sin embargo, debido a sus peculiaridades métricas, el endecasílabo italiano evolucionó de otro modo. Mientras que la sílaba es la unidad mínima del verso español, el verso inglés tiene como unidad mínima el pie poético, es decir «the syllable group surrounding equal space in time» (Lévy 2011: 219). El verso seleccionado por la mayoría de los sonetistas anglosajones es el pentámetro, un verso de cinco pies cuyo número de sílabas puede variar «between nine and twelve syllables before they risk losing the sense of their meter» (Carper y Attridge 2007: 102-103), pues cada pie suele constar de dos o tres sílabas. Encontramos, por tanto, una diferencia principal entre ambos sistemas que el traductor deberá adaptar en su texto de llegada:

The basis of Spanish rhythm is isosyllabism (i.e. equal syllable count corresponding rhythmic segments), whereas the basis of English rhythm is foot isochrony (i.e. more or less equal duration of feet, regardless of the number of syllables contained in them) (Lévy 2011: 219).

En cuanto al ritmo, este viene marcado por los acentos fuertes y débiles (beats/ offbeats o stressed/unstressed) en la métrica inglesa. Tradicionalmente, el soneto inglés se ha escrito empleando el pentámetro yámbico, que consiste en «ten syllables (plus or minus one) with the stressed syllables in even-numbered positions» (Fabb y Halle 2008: 44). Este ritmo yámbico también existe en español y se produce cuando la sílaba sobre la que va situada el acento estrófico (el de la penúltima sílaba) es de signo par; si esta es de signo impar, lo llamamos ritmo trocaico. Como explica Quilis, «todos los demás acentos del verso cuyo signo, par o impar, coinciden con el estrófico, son acentos rítmicos, y los que no coinciden son acentos extrarrítmicos» (Quilis 1978: 28). Los acentos en sílabas pares de los versos yámbicos benefician, por tanto, este ritmo. También Shakespeare empleó para sus composiciones este metro, entre otros recursos que veremos a continuación.

\subsection{Los Sonetos de Shakespeare}

En 1609, el editor londinense Thomas Thorpe publicó un volumen titulado SHAKESPEARES SONNETS que comprendía 154 sonetos inéditos. Se trata de la colección más amplia de sonetos del repertorio renacentista (Spiller 1992: 150). Sin embargo, 
si nos atenemos al esquema tradicional inglés, tres de ellos no entrarían en la categoría mencionada: por un lado, el poema 99 comienza con un quinteto (ABABA) en lugar de un cuarteto, con lo que el poema resultante consta de 15 versos; por otro lado, el soneto 145, pese a mantener el esquema del soneto inglés está escrito en tetrámetros yámbicos (versos de cuatro pies), en lugar de pentámetros -su longitud silábica lo haría equiparable al sonetillo español (un soneto en versos octosílabos)-; y por último, el soneto 126, consta tan solo de 12 versos, pues carece de pareado final, Spiller señala como causa que Shakespeare no pudiese supervisar la impresión, en la que se habrían perdido esos dos versos, ni revisar la versión final, aunque seguramente nunca sabremos si fue algo accidental, como indica Spiller, o un giro deliberado del autor (Spiller 1992: 151).

El resto de los poemas mantienen el esquema tradicional, tres cuartetos y un pareado final, cada estrofa con rima independiente (ABAB CDCD EFEF GG), excepto en el soneto 135, con rima $\mathrm{ABAB} B \mathrm{BCBC} \mathrm{ADAD} \mathrm{AA}$, y el soneto 46, en el que la rima del último cuarteto se extiende al pareado, EFEF FF.

En cuanto al verso, ya habíamos apuntado que Shakespeare emplea el pentámetro yámbico (con la excepción del soneto 145), es decir, un verso de cinco pies en el que se alternan acentos débiles y fuertes. Sirva como ejemplo este análisis del primer cuarteto correspondiente al soneto 18 , en el que las sílabas con acento fuerte están resaltadas en cursiva y los pies aparecen subrayados:

\section{Shall I compare thee to a sum-mer's day?}

Thou art more lovely and more temperate:

Rough winds do shake the darling buds of may,

And summer's lease hath all too short a date.

En lo que concierne a la rima, Shakespeare, al igual que la mayoría de los poetas anglosajones emplea la consonante o total ya que «vowel or vocalic harmony is realtively rarely found in Germanic literatures; it is mainly used to imitate foreign forms» (Lévy 2011: 251), al contrario de lo que sucede en la lírica española, en la que esta rima consonante comparte protagonismo con la rima asonante o parcial. Además, es predominantemente aguda (o masculina), mientras que en nuestra lengua, al igual que en italiano, se emplea la rima grave (o femenina). Como señala Fuller, el efecto musical que se logra en estas dos lenguas mediante la rima femenina es imposible en inglés. El autor afirma que el resultado de esta práctica en la lengua germánica puede resultar tedioso (Fuller 1984: 18). Por tanto, esta propiedad «is not a matter of free choice on the part of the author but a consequence of the fact that the rhyme pattern is language-specific» (Lévy 2011: 239).

A tal reto y a otros que se derivan de las características que hemos explicado se han enfrentado los traductores de estos sonetos de diferentes formas, como observaremos en nuestro análisis.

\section{Análisis del ritmo y la rima en las traducciones de la obra}

Como esbozábamos en el apartado dedicado a la selección del corpus, vamos a analizar, siguiendo el orden cronológico de las publicaciones, el ritmo y la rima en las traducciones seleccionadas de los Sonetos de Shakespeare con el fin de establecer más 
adelante el grado de similitud de estos dos aspectos entre ellas y la obra original. Nos centraremos en aquellos elementos en los que los traductores hayan optado por una estrategia general que busque esa similitud -como la regularidad métrica, el empleo de un patrón rítmico o la búsqueda de la rima- y describiremos, cuando adquieran mayor relevancia, las licencias métricas de las que se han servido para lograr estos objetivos.

Para determinar el ritmo de estos versos, hemos atendido no solo a su medida, sino también a la alternancia que muestran entre sílabas tónicas y átonas, ya que la versificación española se basa en el ritmo intensivo o acentual (Quilis 1978: 21). No obstante, debemos aclarar que un verso puede tener varias lecturas, pues los acentos prosódicos no han de coincidir necesariamente con los acentos métricos (Domínguez Caparrós 2005: 29). En los versos en los que estas posibles realizaciones eran múltiples, hemos optado por interpretar aquellas que se ajustaban mejor al ritmo regular del poema (siempre que hubiese uno). Por ejemplo, si el traductor había optado por verter el pentámetro yámbico inglés en endecasílabos heroicos en la mayor parte de los versos, pero alguno de ellos podía recitarse como heroico o como sáfico, consideramos lógico deducir que el fin del traductor era crear un endecasílabo del primer tipo, aunque para ello tuviera que recurrir a licencias métricas. Si bien la rima es un efecto sonoro que afecta al ritmo del verso, hemos decidido tratarlo de forma aislada con el fin de que su análisis resulte más claro y las respuestas a nuestras preguntas iniciales, más precisas.

La primera traducción que vamos a comentar corrió a cargo de Carlos Pujol ${ }^{1} \mathrm{y}$ apareció publicada por la editorial Comares en 1990. Pujol recurre al verso alejandrino para verter el pentámetro inglés. Si bien en algún caso aislado no se amolda a este patrón, son solo 9 las excepciones entre los 2155 versos con que cuenta la obra. Además, salvo contadas excepciones (5), el ritmo de estos versos es anapéstico, es decir, cada tres sílabas aparece un acento empezando por la tercera; así el esquema rítmico, en el caso del alejandrino, se compone de dos hemistiquios de siete sílabas con acentos en la $3^{\mathrm{a}}$ y $6^{\mathrm{a}}$. La representación de este metro, denominado alejandrino melódico puro, sería la siguiente: ooóooóo/ooóooóo. Para lograr esta regularidad, el traductor se ayuda de las licencias métricas. Por una parte, se emplea la sinalefa a lo largo de todo el poemario (como viene siendo habitual en la versificación española), con lo que se pierden una o varias sílabas en el cómputo final;

si te_olvidas de ti para ser padre de_otros (soneto 14)

No_admiré la blancura que_ostentaban los lirios (soneto 98).

Con este mismo fin, Pujol utiliza la sinéresis;

Atenuando tus culpas cuando no lo merecen (soneto 35)

mientras corre tras ella la criatura llorando (soneto 143).

También para ceñirse al alejandrino, se aprovecha de dos licencias métricas que le permiten sumar una sílaba más, la dialefa y la diéresis;

Como \| un torpe actor que una vez en escena (soneto 23)

pero entonces empieza en mi mente un vi-aje (soneto 27)

las distancias cru-eles no serían obstáculo (soneto 44). 
Ya hemos indicado que Pujol busca el ritmo anapéstico y para lograrlo tiene que servirse en numerosas ocasiones de estrategias de acentuación y desacentuación. Esto es posible cuando «el esquema habitual es muy evidente en un poema» (Domínguez Caparrós 2005: 36), como ocurre en estos versos;

Corazón de mujer pero sin la costumbre (soneto 20)

Borrar esta presencia de tu vida en nosotros (soneto 55).

Nos referimos anteriormente a los nueve casos en los que no se emplea el alejandrino; pues bien, en ocho de ellos ocurre algo llamativo que creemos conveniente explicar a partir de tres ejemplos:

La verdad y la belleza juntas van a medrar (soneto 14)

Lealtad a cuyo lado un ingenio tan romo (soneto 26)

A no ser que establezcan la maldad universal (soneto 121).

En estos tres versos y en los cinco restantes el cómputo final es de 15 sílabas en lugar de 14; esto sucede cuando recitamos el poema ajustándonos a la variedad normativa del español de España. Sin embargo, al adoptar el habla de algunas variedades diatópicas, como la andaluza, o de un registro informal, eliminamos la 'd' al final de palabra (/laberdá/) y podemos realizar la sinalefa (/laberdáilabele $\theta \mathrm{a} /$ ); con lo que se mantienen las 14 sílabas:

La verda(d) y la belleza juntas van a medrar (soneto 14)

Lealta(d) a cuyo lado un ingenio tan romo (soneto 26)

A no ser que establezcan la malda(d) universal (soneto 121).

Pujol no presta en ningún caso atención a la rima y ni siquiera la nombra en su prólogo, por lo que sus poemas están compuestos enteramente de versos sueltos.

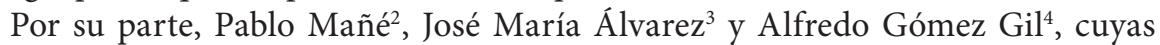
traducciones aparecen publicadas en los años 1992, 1999 y 2000, respectivamente, rechazan la búsqueda de cualquier similitud de ritmo y rima con el original. Ambos dividen sus poemas en 14 líneas, pero hasta aquí llega su trasvase de la forma. Las traducciones de Mañé recuerdan más a la prosa que al verso, mientras que las de Álvarez y Alfredo Gil emplean versos blancos de muy diversas longitudes.

La editorial Hiperión publica en 2005 los Sonetos de Shakespeare en una versión de Gustavo Falaquera ${ }^{5}$, aunque la traducción pertenece al año 1993. En ella, Falaquera utiliza el alejandrino blanco y prescinde de la rima. He aquí el segundo cuarteto del soneto 114 en el que se observa la diversidad rítmica que introduce en sus versos:

[...] de convertir los monstruos y seres imposibles (4.6/2.6)

en dulces querubines parecidos a ti, (2.6/3.6)

haciendo de lo malo la perfección mayor (2.6/4.6)

en cuanto los objetos a su mirada surgen? (2.6/4.6).

No ocurre lo mismo en la traducción realizada por Antonio Rivero Taravillo ${ }^{6}$ (Renacimiento, 2004), en la que emplea el verso endecasílabo pues, como él mismo explica en el prólogo «cuando uno se dispone a leer un poema culto del siglo XVI 
sólo espera once sílabas y un acento en sexta u octava» ${ }^{7}$. El traductor se ciñe a esta medida en la mayor parte de los casos, si bien en 39 de los versos (de los 2155) el cómputo silábico pasa de esa cifra. En 34 de esas excepciones se repite el mismo fenómeno: aparecen tres o más vocales contiguas en algún lugar del verso, cuya sinalefa permitiría mantener el endecasílabo.

Cuando extraño a la fortuna y a los hombres (soneto 29)

Tal guerra civil hay entre mi amor y odio (soneto 35)

En mejillas sin sangre y a ti te sobra (soneto 82)

A la fuerza soy tuyo, y cuanto hay en mí (soneto 133).

No sabemos si este patrón aparece en esos 34 versos de forma accidental o si el traductor buscaba una sinalefa que las leyes fonéticas imposibilitan-recordemos que la sinalefa puede contener grupos de hasta seis vocales «con tal de que estén dispuestas en orden de progresiva abertura, de progresiva estrechez, o con las más abiertas en el centro» (Domínguez Caparrós 2005: 14)-, pero el resultado es siempre en estos casos un verso dodecasílabo.

Para lograr crear los endecasílabos, el traductor se ve obligado en ocasiones a realizar sinalefas excesivamente forzadas, como las del siguiente ejemplo:

a cuanto himno eleva ese espíritu_hábil (soneto 85)

Respecto al ritmo, Rivero Taravillo emplea el verso blanco, si bien utiliza mayoritariamente versos con acento en $6^{\mathrm{a}} \mathrm{u} 8^{\mathrm{a}}$ (excepto en 42 casos), como afirma en su prólogo, pero los ritmos son muy diversos y en la traducción aparecen prácticamente todas las combinaciones posibles que incluyen estos dos acentos. En el siguiente ejemplo (s. 107) podemos leer uno de esos versos que no respetan el acento en $6^{\mathrm{a}}$ ni $8^{\mathrm{a}}$ :

Con las gotas de este tiempo balsámico (3.7.10)

El traductor rechaza desde un principio la rima y explica la razón en el prólogo:

Despachemos primero el asunto de la rima: Shakespeare la empleó porque era el uso de su época y tradición. Como unos siglos antes se estiló la poesía aliterativa. Hoy, un lector de poesía, de la poesía que hoy se escribe en nuestra lengua (pero también en la inglesa, por ejemplo), no solo no precisa de la rima sino que por lo general prefiere la musicalidad del verso repartida en su conjunto a la marcada identidad de los finales de éste, en parte por el agotamiento de las posibles rimas consonantes, con el efecto que producen de leer algo manido, cuando no ripioso. ${ }^{8}$

Sin embargo, sí que la emplea en el soneto 18 por «experimentar»y porque, afirma, «el original se prestaba a ello».

Ignacio Gamen ${ }^{9}$ (Renacimiento 2009) es el primero de estos traductores en buscar la rima en su versión en español. Emplea, predominantemente, la rima asonante aunque, como indica en su prólogo, no eliminó la rima consonante en los casos en los que «surge natural $»^{10}$. De las 1077 rimas de que consta el poemario, solo 101 son consonantes y, ciertamente parece algo accidental pues muchas de ellas se basan en palabras que poseen la misma categoría gramatical, como plasmarimitar (soneto 16) formado-asignado (soneto 53), vergonzosos-amorosos (soneto 51), podían-crecían (soneto 98) o recordarte-olvidarte (soneto 122). Solo en un caso no 
mantiene la rima, en los versos impares del segundo cuarteto perteneciente al soneto número 60:

$$
\begin{gathered}
\text { El hombre, cuando nace, envuelto en luz discurre } \\
\text { radiante por la vida hasta su madurez. } \\
\text { Su luz y gloria, entonces, los eclipses ocultan } \\
\text { y el tiempo le arrebata lo que le diera ayer. }
\end{gathered}
$$

El verso que escoge es el alejandrino, pese a expresar que es «una lástima» pues aprecia mucho «la sonoridad y elegancia del endecasílabo» ${ }^{11}$ y mantiene esta medida a lo largo de todo el poemario. Sin embargo, en lo que concierne al ritmo, si bien entre sus versos hay un mayor número de alejandrinos heroicos puros (con acentos en $2^{\mathrm{a}}$ y $6^{\mathrm{a}}$ en cada hemistiquio), no hay un patrón rítmico que abarque toda la traducción y se mezclan en ella todo tipo de combinaciones acentuales.

Andrés Ehrenhaus ${ }^{12}$ (Galaxia Gutenberg 2009) sostiene en su prólogo que ha empleado el endecasílabo con ritmo yámbico y argumenta su decisión del siguiente modo:

Encuentro más fiel, o más fácil, o más seguro, o más coherente con el proceso íntimo de la traducción, aceptar y sistematizar la pérdida que verme obligado a llenar el vacío, porque no es infrecuente que al verso alejandrino le sobren sílabas: el traductor puede decir menos que el autor, pero nunca más. ${ }^{13}$

Más adelante añade que además se impuso como condicionante que sus endecasílabos fuesen yámbicos, «es decir, fieles al ritmo binario de los pentámetros shakespearianos». Y cumple con estos dos propósitos, pues todos los versos están escritos en endecasílabos -excepto el soneto 145, escrito originalmente en tetrámetros y que Ehrenhaus traslada a eneasílabos- con ritmo yámbico, alternando heroicos (con acentos en $2^{\mathrm{a}}, 6^{\mathrm{a}}$ y $\left.10^{\mathrm{a}}\right)$ y sáficos $\left(4^{\mathrm{a}}, 8^{\mathrm{a}}\right.$ y $\left.10^{\mathrm{a}}\right)$ en sus diferentes variedades, como se puede comprobar en el siguiente cuarteto perteneciente al soneto 66 :

$$
\begin{gathered}
\text { y que la autoridad censure el arte, (6.8.10) } \\
\text { y la locura cure lo sensato, (4.6.10) } \\
\text { y tachen de simpleza las verdades, (2.6.10) } \\
\text { y viva el bien cautivo de lo malo. (2.(4).6.10) }
\end{gathered}
$$

Como se puede observar, emplea la rima asonante y defiende que lo hizo para «suavizar la rigidez y el repiqueteo (iy esquivar los ripios!) de la consonancia castellana». ${ }^{14}$

Christian Law Palacín ${ }^{15}$ (Bastleby 2009) emplea el endecasílabo para verter el pentámetro y lo hace porque, indica, es una decisión que «el oído acaba agradeciendo ${ }^{16}$. No sigue, en cambio, un patrón regular para el ritmo, ya que opta por el verso blanco (aunque mantiene el acento en $6^{\mathrm{a}} \mathrm{u} 8^{\mathrm{a}}$ ), como hace en el siguiente cuarteto del soneto 40:

Ódiame cuando quieras; hazlo ahora (1.6.8.10)

que el mundo se dispone a desairarme,(2.6.10)

Únete a la fortuna en su desprecio, (1.6.10)

humíllame, no esperes a la calma (2.6.10) 
La rima, como se aprecia en estos mismos versos, no aparece tampoco en su traducción.

Ramón Gutiérrez Izquierdo ${ }^{17}$, cuya traducción publica Visor en el año 2011, explica de la siguiente manera por qué decidió traducir los pentámetros shakespearianos en alejandrinos, en lugar de hacerlo en endecasílabos:

No me pareció apropiado emplear este molde [el endecasílabo] para verter los sonetos a una lengua romance, pues de hacerlo debería mutilar inevitablemente los versos, debido a que más del $75 \%$ del léxico utilizado incluye monosílabos anglosajones. Por eso consideré que el metro idóneo para verte los Shakespeare's Sonnets a una lengua romance era el alejandrino. ${ }^{18}$

Sin embargo, para mantener el alejandrino, Gutiérrez Izquierdo se ha visto obligado a recurrir a licencias métricas que, en ocasiones, resultan demasiado forzadas, como estas dos dialefas que obligan a acentuar el determinante:

Probando tu \| herencia con su \| hermoso aspecto (s. 2);

o estas otras:

¡Si a ti te \| heredases!; pero,\| amigo apenas (s. 13),

necesarias no solo para lograr un verso alejandrino, sino también un ritmo yámbico.

No emplea un ritmo definido a lo largo de toda la obra, aunque sí hay una abundancia de alejandrinos heroicos (6 de cada 10 versos siguen este patrón rítmico).

Para la rima, Gutiérrez Izquierdo se rige por un criterio heterogéneo, utiliza la rima asonante en los versos impares y la consonante en los pares y en el dístico final, como señala en el prólogo.

Y para estar seguro de que no juro en falso, suspiros a millares si evoco tu semblante, uno detrás de otro dan testimonio franco de que tu cara negra juzgo la más radiante.

En nada eres oscura, salvo en comportamiento, y en él pienso que toma esa calumnia asiento. (s. 131)

La última traducción en español publicada hasta la fecha en nuestro país es la de Bernardo Santano Moreno ${ }^{19}$, que salió a la luz de la mano de la editorial Acantilado en el 2013. Utiliza en su versión castellana el verso endecasílabo, aunque incluye para cada poema una traducción en prosa en forma de nota al pie. El ritmo varía a lo largo de los versos, no obstante todos ellos llevan tres acentos, el penúltimo en $6^{\mathrm{a}} \mathrm{u} 8^{\mathrm{a}}$, y predominan los endecasílabos heroicos puros (2.6.10), los melódicos puros (3.6.10) y los sáficos cortos (4.6.10). Es el único de nuestros traductores que mantiene la rima consonante en todos los sonetos, incluso en algunos casos esta se extiende al siguiente cuarteto o al pareado final, como ocurre en el soneto 144:

Para hundirme la mala en el infierno

al bueno tienta lejos de mi lado,

corrompería al santo hacia el averno,

rondando su virtud con ruin agrado. 


\author{
Y si en demonio mi ángel se ha tornado \\ lo puedo sospechar, mas no es seguro; \\ lejos de mí, los dos se han amistado, \\ $y$ en el infierno de uno al otro auguro.
}

Vistas estas características referentes al ritmo y la rima, pasaremos ahora a contrastarlas con las de los poemas originales para comprobar su grado de similitud.

\title{
4. Resultados y conclusiones
}

Como afirmaban varios de los traductores cuyos trabajos han servido de base a este estudio, el verso considerado más apto para verter el pentámetro yámbico al español es el endecasílabo, concretamente aquel que posee un ritmo yámbico (con acento en las sílabas pares). Rivero Taravillo ampliaba este margen afirmando que el verso debía tener acento en las sílabas $6^{\mathrm{a}} \mathrm{u} 8^{\mathrm{a}}$. Tras observar los Sonnets originales y sus traducciones al español, y ateniéndonos a criterios métricos y, por tanto, melódicos, consideramos que tan importante como esos dos acentos es la existencia de un periodo rítmico regular, un patrón que se repita a lo largo de todo el poema y, por extensión, de todo el poemario. Esta es una característica esencial del ritmo del poemario original y creemos que su pérdida alteraría la melodía final. Así, hemos establecido varios grados de similitud de mayor a menor, siempre teniendo en cuenta que las distintas soluciones no se encuentran equidistantes, sino que las traducciones que no buscan ningún tipo de regularidad métrica, ni de medida ni de patrón acentual, están muy alejadas de aquellas que sí lo hacen:

- Traducción en endecasílabos con ritmo yámbico puro (con acentos solo en sílabas pares), como es el caso de la traducción de Ehrenhaus que, pese a alternar distintas variedades de versos yámbicos siempre mantiene los acentos en sílabas pares. Hemos situado esta forma en primer lugar por su parecido tanto en el cómputo silábico de cada verso, como en el ritmo acentual. Si bien es cierto que cada verso original cuenta con 5 acentos (beats), debido a las propiedades de la lengua española, consideramos que, aunque sí es posible crear un verso con cinco acentos en sílabas pares (2.4.6.8.10), su uso durante todo el poema no solo resultaría excesivamente complejo, sino que lo dotaría de un ritmo enormemente marcado. Esto no sucede en el original, compuesto en una lengua con gran abundancia de monosílabos en la que esa alternancia de sílabas acentuadas e inacentuadas (beats/offbeats) es mucho más natural y no causa extrañeza al oído. En la traducción se opta por un esquema de tres acentos que es práctica habitual entre los poetas españoles que cultivan el endecasílabo.

- Traducción en endecasílabos con ritmo yámbico mixto (siempre que haya cierta regularidad a lo largo de toda la obra y no predominen más de dos o tres variedades), como el empleado por Law Palacín o Santano Moreno. Como indicábamos más arriba, nos parece que una regularidad rítmica es más importante que mantener simplemente el acento en $6^{\mathrm{a}} \mathrm{u} 8^{\mathrm{a}}$, como sostenía Rivero Taravillo. Ciertamente este acento beneficia al ritmo yámbico, como lo hace en las traducciones de Law Palacín y de Santano Moreno, pero estos dos traductores, además de mantener este acento que sirve de apoyo al estrófico lo incluyen solamente en dos o tres combinaciones predominantes durante todo el poemario, mientras que Rivero Taravillo incluye muchas más variedades posibles dentro de su traducción, con lo que se pierde esa homogeneidad que consideramos clave. 
- Traducción en alejandrinos con ritmo yámbico puro o mixto (siempre que se componga de periodos rítmicos regulares). Hemos optado por insertar en este punto el alejandrino debido a la condición de «verso de ritmo endecasilábico» que se le otorga en métrica debido a sus cualidades rítmicas y que hacen de él un verso idóneo para combinar con el endecasílabo (Torre, 2000:76). No existe en nuestro corpus ninguna traducción que emplee el alejandrino con ritmo yámbico puro. Sin embargo, la de Carlos Pujol se adecúa a este segundo criterio al emplear el alejandrino anapéstico en la práctica totalidad de sus poemas.

- Traducción en endecasílabos con acento en $6^{\mathrm{a}} \mathrm{u} 8^{\mathrm{a}}$ que no siguen un patrón rítmico definido e incluyen más de tres variedades predominantes. Como acabamos de explicar, este es el caso de la versión de Rivero Taravillo.

- Traducción en alejandrinos blancos. En este lugar se situarían las traducciones de Gustavo Falaquera, Ramón Gutiérrez Izquierdo e Ignacio Gamen. Como hemos dicho, por su condición de verso endecasilábico, la elección del alejandrino no nos parece disparatada, aunque es cierto que su longitud y su consecuente ruptura en hemistiquios alteran el ritmo del original. Estos tres traductores lo emplean sin fijarse un patrón rítmico, aunque en Gutiérrez Izquierdo se observa una mayor coherencia rítmica.

- Por último, y muy alejadas de las anteriores se encontrarían las traducciones en verso libre, como la de José María Álvarez, la de Alfredo Gómez Gil o la de Pablo Mañé. Estas traducciones, si bien pueden tener una similitud importante en el plano semántico -pero esto no nos atañe-, en el trasvase formal se pierde todo lo que distingue al poema original. Por esta razón afirmábamos que se encuentran muy alejadas de las anteriores, pues no se trata de que el ritmo y la rima que han empleado no recuerden al original inglés tanto como las otras opciones, sino que estos dos aspectos son ignorados desde un principio.

En lo tocante a la rima y pese a que en inglés se emplea la rima total o consonante, un acercamiento a esta por medio de una rima asonante en español no nos parece del todo inadecuada, pues como señalábamos en el apartado 2.3, en inglés esta apenas se emplea o solo se hace para imitar formas extranjeras (cf. Lévy 2011: 251), mientras que en español cuenta con una larga tradición y no posee un carácter tan marcado como la consonante. Dicho esto, no podemos ignorar que el soneto en nuestra tradición ha venido empleando principalmente la rima consonante, por lo que la correspondencia más lógica en español para la rima consonante inglesa parece ser también otra rima consonante. De los traductores incluidos en nuestro análisis, solo Santano Moreno la ha empleado en la totalidad de la obra, mientras que Gutiérrez Izquierdo la alterna con la rima asonante y la emplea en 8 de cada 14 versos. Gamen y Ehrenhaus, por su parte, se decantan por la rima asonante, y aunque el primero acude a la consonante en algunos casos, el número total no es significativo. Las siete traducciones restantes, sin embargo, prescinden totalmente de la rima.

Teniendo en cuenta los parámetros y resultados extraídos que acabamos de enumerar, podemos responder a nuestra primera pregunta -aquella que planteaba si traductor de poesía opta por verter el poema original en una traducción en verso o en prosa. Puesto que las once traducciones analizadas emplean el verso, la respuesta parece evidente.

Nuestro segundo interrogante giraba en torno al ritmo. Nos preguntábamos al inicio del estudio si el traductor, siempre teniendo en cuenta las diferencias métricas entre los sistemas de las dos lenguas con las que trabaja, decidía trasladar a la lengua meta el ritmo original. Ya apuntábamos entonces que esta cuestión que nos ocupa era más difícil de comprobar, puesto que sus límites no están tan claros como en el 
caso de la prosa frente al verso. Pese a todo, creemos que es evidente la búsqueda de un ritmo por parte de los traductores pues, como hemos observado, solo tres de los traductores optaron por rechazar un molde rítmico para sus versiones, mientras que los ocho restantes buscaron algún tipo de regularidad métrica que evocase a la del soneto original. Pese a que, como hemos indicado, estos últimos lo logran en diferente medida y ese deseo de semejanza formal aparece en distintos grados, consideramos que la respuesta es afirmativa.

Nos preguntábamos, por último, si el traductor de los sonetos busca un efecto sonoro equivalente en el poema de llegada basado en la rima, sin olvidar las peculiaridades de este elemento tanto en el sistema de la lengua de ambos idiomas, como en su tradición lírica. Únicamente en cuatro de las traducciones se cumple esta máxima, con lo que la debemos responder con un contundente «no».

Law Palacín afirmaba en su prólogo que había renunciado tanto a un ritmo regular como a la rima en su traducción, y explicaba:

La lengua de nuestro autor es ya clásica -antigua- y lo es tempestuosamente, y la del traductor, obligado con todo a conservar ese clasicismo, debe ser además tan moderna como la de Shakespeare lo era en el siglo XVI, y por ello, entiendo, más ligera su música sin empobrecerse, más hecha para nuestra era). ${ }^{20}$

Este parece un argumento lógico para prescindir de la regularidad rítmica y de la rima. Sin embargo, en nuestra era y en nuestra lírica -y eso parece olvidarlo Law Palacín-, la forma de soneto que sigue imperando es la misma que cultivaran Garcilaso, Quevedo o Lope hace ya varios siglos.

Rivero Taravillo, por su parte, sostenía que lo que un lector espera ante un poema del siglo XVI son once sílabas ${ }^{21}$. No hay nada que objetar a eso. Sin embargo, previamente «despachaba» el asunto de la rima por no ajustarse a los parámetros de la poesía actual. Nos preguntamos entonces por qué el traductor emplea dos criterios diferentes para cada uno de estos dos recursos. ¿Qué hace que el alejandrino, por ejemplo, sea demasiado moderno y la rima demasiado rancia?

Desde su invención, el soneto ha adquirido formas muy diversas y ha contenido expresiones muy alejadas entre sí. Aunque los sonetos en endecasílabos son los que siguen gozando aún hoy día de mayor fama, se han escrito este tipo de composiciones con alejandrinos, dodecasílabos, octosílabos, pentasílabos..., incluso heterométricos. También adquirieron formas y esquemas muy variados (algunos de los cuales ya vimos cuando hablamos de la evolución del soneto), que hasta superaron los 14 versos, como el soneto con estrambote, que incluía un terceto más. Se han cultivado sonetos de expresión elegiaca, amorosa, satírica... Sin embargo, a lo largo de su historia hay un aspecto que ha ido siempre de la mano de este subgénero lírico: la rima. Está claro que en la actualidad la rima no es una característica inherente al verso, pero no cabe duda de que sí es inherente al soneto. Cabría pensar, pues, que esta tuviese para los traductores -si no en el resultado, sí en su ambición traductoraal menos el mismo peso que el ritmo, cuando no mayor.

Por otro lado, no podemos olvidar que la creación de una composición poética prescrita como es el soneto nunca es fortuita, el autor debe plantearse como objetivo respetar unas características formales que constituyen los fundamentos de tal poema. Para someterse a este molde tendrá, necesariamente, que jugar con el plano semántico y enmendar versos, llegando incluso a prescindir de ciertas expresiones o imágenes que no tienen cabida en la horma que se ha impuesto. Si el propio autor concede tanta 
importancia a estos aspectos como para transformar el entramado semántico en pro de una rima, ¿qué lleva al traductor a desdeñarla?, ¿en qué criterios se basa para considerar que traducir la obra poética de un autor significa verter a otra lengua sus palabras pero no su melodía? Estos interrogantes, que parecen haber sido desterrados de las reflexiones, constituyen el objeto mismo de este estudio.

Para finalizar, nos gustaría comentar un aspecto que, si bien no compete a este trabajo, pues no está dentro de sus objetivos, nos parece relevante. Mientras que las seis primeras traducciones de este estudio, las publicadas entre 1990 y 2005, no reflejaban la rima en sus versos, cuatro de las cinco más recientes (dos correspondientes a 2009, una a 2011 y la última a 2013) sí que la emplean; de esas cuatro las dos primeras utilizan la rima asonante, en la tercera se mezclan rima asonante y consonante siguiendo un patrón y la última es la única que guarda la rima consonante. Se observa por tanto una tendencia en esas traducciones más recientes a buscar una mayor similitud en la rima respecto del original. Como indicamos, comprobar esta tendencia en la traducción del verso rimado no es el objetivo de este trabajo, ya que lo reducido del corpus no lo permitiría, pero podría servir de base para un estudio más ambicioso, dotado del aparato teórico de los estudios de traducción, que contribuya a redefinir las normas contemporáneas de la traducción literaria de la poesía en español

\section{AGR ADECIMIENTOS}

Quiero dar las gracias al profesor Anxo Fernández Ocampo por guiarme sabiamente y por formularme preguntas en lugar de darme respuestas.

\section{NOTAS}

1. William Shakespeare (1990): Sonetos (Traducido por Carlos Pujol). Granada: Comares.

2. William Shakespeare (1992): Los sonetos (Traducido por Pablo Mañé Garzón). Barcelona: Ediciones 29.

3. William Shakespeare (1999): Sonetos (Traducido por José María Álvarez). Madrid: Pre-textos.

4. William Shakespeare (2000): Los sonetos de Shakespeare (Traducido por Alfredo Gómez GiL). Madrid: Edaf.

5. William Shakespeare (2005): Sonetos (Traducido por Gustavo Falaquera). Madrid: Hiperión.

6. William Shakespeare (2004): Sonetos (Traducido por Antonio Rivero). Sevilla: Renacimiento.

7. (Shakespeare 2004: 17)

8. (Shakespeare 2004: 16)

9. William Shakespeare (2009a): Sonetos de amor (Traducido por Ignacio Gamen). Sevilla: Renacimiento.

10. (Shakespeare 2009a: 31)

11. (Shakespeare 2009a: 30)

12. William Shakespeare (2009b): Sonetos y Lamento de una amante (Traducido por Andrés Ehrenhaus). Barcelona: Galaxia Gutenberg.

13. (Shakespeare 2009b: 50)

14. (Shakespeare 2009b: 21)

15. William Shakespeare (2009c): Sonetos (Traducido por Christian Law Palacín). Madrid: Bartleby.

16. (Shakespeare 2009c: 10)

17. William Shakespeare (2011): Sonetos de Shakespeare. Shakespeare's Sonnets (Traducido por Ramón GutiÉrReZ IzQuierdo). Madrid: Visor.

18. (Shakespeare, 2011: 22)

19. William Shakespeare (2013): Sonetos (Traducido por Bernardo Santano Moreno). Barcelona: Acantilado.

20. (Shakespeare 2009c: 10)

21. (Shakespeare 2004: 17) 


\section{REFERENCIAS BIBLIOGRÁFICAS}

Borges, Jorge Luis (1997): «Las dos maneras de traducir». In: Jorge Luis Borges, Textos recobrados 1919-1930. Buenos Aires: Emecé, 256-259. Consultado el 6 de mayo de 2015, <http:// www.cervantesvirtual.com/obra/las-dos-maneras-de-traducir/>.

Carandell, Zoraida, Laget, Laurie-Anne y Lecointre, Melissa (2006): Traduire le poème en prose: Le rythme dans Los Placeres Prohibidos de Luis Cernuda, Centre de recherche sur l'Espagne contemporaine. Consultado el 13 de frebrero de 2015, <http://crec.univ-paris3.fr/ Traduirelepoemeenprose.pdf $>$.

Carper, Tomas y Attridge, Derek (2007): Meter and Meaning. An introduction to Rhythm in Poetry. Nueva York: Routledge.

De Beaugrande, Robert (1978): Factors in a Theory of Poetic Translating. Assen: Van Garcum. Domínguez Caparrós, José (2005): Elementos de métrica española. Valencia: Tirant lo Blanch. FabB, Nigel y Halle, Morris (2008): Meter in Poetry. Cambridge: Cambridge University Press. FulLER, John (1984): The Sonnet. Nueva York: Methuen.

Hurtado Albir, Amparo (1990a): «La fidelidad al sentido: problemas de definición». In: Margit RAders y Juan ConesA, eds. II Encuentros Complutenses en Torno a la Traducción: 12-16 de diciembre de 1988. Madrid: Editorial Complutense, 57-64.

Hurtado Albir, Amparo (1990b): La notion de fidelité en traduction. París: Didier Erudition. LevÝ, Jiří (2011): The Art of Translation. Filadelfia: John Benjamins Publishing Company.

López Hernández, Marcela (1998): El soneto y sus variedades. Salamanca: Ediciones Colegio de España.

Morales Barba, Rafael (1996): «Poesía y traducción». Trans. 1:179-181. Consultado el 6 de marzo de 2015, <http://www.trans.uma.es/pdf/Trans_1/t1_179-181_RMorales.pdf>.

Muñoz Calvo, Micaela (1987): Ediciones y traducciones españolas de los sonetos de William Shakespeare: Análisis y valoración crítica. Zaragoza: Secretariado de publicaciones de la Universidad de Zaragoza.

Navarro Tomás, Tomás (1995): Métrica española. Barcelona: Editorial Labor.

Quilis, Antonio (1978): Métrica española. Madrid: Ediciones Alcalá.

ShaKespeare, William (2003): Obras completas (Traducido por Luis Astrana Marín). Madrid: Aguilar.

SpILLER, Michael R. G. (1992): The Development of the Sonnet. Londres: Routledge.

Varela Merino, Elena, Moíño Sánchez, Pablo y Jauralde Pou, Pablo (2005): Manual de métrica española. Madrid: Castalia.

Venuti, Lawrence (1995): The Translator's Invisibility. A History of Translation. Londres: Routledge. 